\title{
Una aproximación al universo ideológico de la Central Latinoamericana de Trabajadores a través de su proyecto de formación política (1954-1977)
}

An approach to the ideological universe of the Central Latinoamericana de Trabajadores through its political training project (1954-1977)

\author{
Gabriela Scodeller
}

Resumen: El artículo explora el devenir político-ideológico de la regional obrera de origen socialcristiano Confederación Latinoamericana de Sindicalistas Cristianos (luego apodada Central Latinoamericana de Trabajadores). Para aproximarnos a la caracterización de un actor cuyos contornos identitarios aparecen difusos y sobre el cual poco se ha indagado, se analiza su proyecto pedagógico; en especial aquél diseñado para atender a la formación política de las bases del movimiento, denominado Proceso Colectivo de Elaboración Ideológica.

Palabras Clave: Sindicalismo cristiano; formación política; organizaciones obreras; América Latina; años setenta.

Abstract: The article explores the political-ideological trajectory of the workers Regional of social Christian origins Latin American Confederation of Christian Trade Unions (later named Latin American Central of Workers). To approach a characterization of an actor whose identity contours appear diffuse and about which little has been investigated, its pedagogical project is analyzed; especially that designed to meet the political training of the rank and file of the movement, called Collective Process of Ideological Elaboration.

Keywords: Christian Trade Unionism; Political training; Workers organizations; Latin America; Seventies.

Recibido: 15 diciembre 2018 Aceptado: 23 marzo 2019

\footnotetext{
*Argentina, Doctora en historia, investigadora CONICET, g_scodeller@yahoo.com.ar
} 


\section{Introducción}

Desde que fue creada en Santiago de Chile en 1954, la Confederación Latinoamericana de Sindicalistas Cristianos (CLASC) agrupó y organizó, a nivel continental, a las y los trabajadores de dicho credo $^{1}$. Con los años amplió su horizonte de representación religiosa, buscando además nuclear no sólo a trabajadores sindicalizados sino a organizaciones de pobladores, cooperativistas, campesinos, mujeres y jóvenes. Transitó un camino propio y original, con autonomía de las instituciones con las cuales se la ha solido identificar, sea la Iglesia Católica, los partidos Demócrata Cristianos, o la propia confederación mundial de la que formaba parte. Su historia se ubica más bien próxima al proceso de radicalización por el que atravesaron distintos sectores religiosos del continente en las décadas del sesenta y setenta, cuyo correlato fue una acelerada dinámica de secularización.

Recordemos brevemente el proceso de cambios acaecidos al interior de la Iglesia católica, cuyo corolario fue el Concilio Vaticano II (1962-1965) y la importante recepción en América Latina de la encíclica Populorum Progressio; el surgimiento de la Pastoral del Tercer Mundo, cuyos obispos ya no condenarían las revoluciones si servían a la justicia; y más cercanamente, las profundas implicancias de la II Conferencia del Episcopado Latinoamericano (CELAM) realizada en Medellín en 1968. A la par, una importante cantidad de grupos identificados en el cristianismo tomaría un rumbo aún más radical, no sólo realizando una opción por los sectores oprimidos del continente (ahora mirados como sujetos de su propia liberación), sino condenando "la violencia de arriba" y comprometiéndose en sus conflictos y luchas -lo que en muchos casos llegó hasta abrazar la lucha armada-. Acompañando este proceso, la Teología de la Liberación realizaba una lectura marxista de la Biblia y de la realidad socioeconómica de la región. No por casualidad, el Informe Rockefeller refería cómo la iglesia latinoamericana se había distanciado del rol conservador que había jugado en la región por más de cuatro siglos, arrimándose a ideas de "cambio social, económico y político" y hasta encontrándose dispuesta a "asumir una revolución si fuese necesario para terminar con la injusticia"2.

En la coyuntura del '68, la CLASC puede ubicarse con la corriente revolucionaria (aunque sin adscribir a la lucha armada y con puntos de diálogo con la línea reformista y desarrollista -continuadora del Concilio Vaticano II-) $)^{3}$. En una posición intermedia, si bien advierte al papa Pablo VI que “... los que tienen hambre y sed de justicia y de pan, los pobres, hablan de revolución en América Latina..."4, no comulga, pero tampoco condena, la opción armada, ya que "la violencia [institucionalizada] llama a la violencia" 5 .

${ }^{1} \mathrm{El}$ artículo utiliza un lenguaje que diferencia sexo cuando refiere a militantes, bases o adherentes a la organización. El uso del masculino en el lenguaje, propio de la época, no significa que la CLASC/CLAT no tuviese una composición femenina importante (no así en sus capas dirigenciales) y políticas específicas para el sector. Si bien no es el foco del artículo, consideramos importante dejar de invisibilizar a las mujeres en los relatos que construimos sobre el mundo del trabajo en la historia reciente.

${ }^{2}$ Nelson Rockefeller, The Rockefeller report on the Americas: the official report of a United States Presidential mission for the Western Hemisphere, Chicago, Quadrangle Books, 1969, 31 (traducción propia).

${ }_{3}^{3}$ Para una caracterización de estas líneas véase Samuel Silva Gotay, El pensamiento cristiano revolucionario en América Latina y el Caribe, Salamanca, Ed. Sígueme, 1981, capítulo 1. La propia organización identificaba tres corrientes dentro de las iglesias latinoamericanas: una tradicionalista, la capitalista y otra revolucionaria. CLAT, Proceso Colectivo de Elaboración Ideológica. Ciclo I: Diagnóstico de la realidad nacional, latinoamericana y mundial, Venezuela, FLACPO, sin fecha, Tema XII, 23.

4 "Ten cuidado, hermano Pablo, porque hay muchos privilegiados y opulentos que esperan que tú hables en Bogotá contra este proceso revolucionario, invitando a los latinoamericanos a entrar en un proceso más bien de 'evolución gradual y pacífica'. Tú debes saber que los que tienen hambre y sed de justicia y de pan, los pobres, hablan de revolución en América Latina". CLASC, Vocero del sindicalismo cristiano en América Latina, Año II, N¹8, septiembre, Caracas, 1968, 1, en International Institute of Social History (IISH).

5 CLASC, Vocero..., Año I, $\mathrm{N}^{\circ}$ 9, diciembre 1967, 2. Llegan incluso a rendir un homenaje al sacerdote guerrillero Camilo Torres al cumplirse dos años de su muerte, afirmando que "la Encíclica El Progreso de los Pueblos, otorga una especie de legitimación a la actitud adoptada por Camilo durante su vida”. CLASC, Vocero..., Año I, Nº12, marzo 1968, 6. Una década 
A su vez, en otras latitudes el mundo sindical cristiano también se veía agitado a su interior. En 1968, en gran parte producto de los cambios demandados desde el Tercer Mundo, la Confederación Internacional de Sindicatos Cristianos (CISC) -a la cual estaba adherida la CLASC- abandonaba el apelativo religioso pasando a denominarse Confederación Mundial del Trabajo (CMT), clamando además por la liberación de los trabajadores y la transformación social ${ }^{6}$. En ese proceso de secularización que atravesaron muchas de las instituciones sindicales cristianas a nivel mundial, el camino recorrido en América Latina tuvo un componente mayor de radicalización política dado el contex to abierto por la Revolución Cubana.

Sin embargo, un repaso por la bibliografía existente permite advertir que la producción en torno a estas temáticas, elaborada desde el campo de la filosofía, historia de las ideas, teología o sociología de las religiones fundamentalmente, no ha reparado en el cruce entre religión y sindicalismo (como sí sucedió para el ámbito europeo -aunque éstos raramente dialogan con las experiencias latinoamericanas- ${ }^{7}$ ). Desde el campo historiográfico, el foco estuvo puesto más bien en el cruce entre religión y organizaciones armadas. Por su parte, los estudios latinoamericanos sobre el mundo del trabajo y las/os trabajadores ha prestado poca atención a la tradición socialcristiana y sus organizaciones, situación que llama la atención si, siguiendo al historiador estadounidense Robert Alexander, consideramos que la CLASC fue la organización sindical de orientación cristiana más importante en la época ${ }^{8}$.

Pero aquí no nos detendremos en su aún poco explorada historia, sino que nos enfocaremos en lo que consideramos el aspecto distintivo de esta organización en relación a otras experiencias de la época: el énfasis que puso en la formación de sus miembros. La importancia otorgada al asunto puede rastrearse desde su nacimiento, para lo cual diseñó una compleja estructura educativa que contemplaba distintos niveles y destinatarios. Siendo la educación obrera (en sentido amplio) una preocupación compartida -con diversas orientaciones y aristas- por el conjunto de las organizaciones internacionales vinculadas al mundo del trabajo en los años de la Guerra Fría; la CLASC depositó el foco en la formación político-ideológica de modo prioritario. Por ello es que esta será nuestra puerta de entrada para intentar aproximarnos a una caracterización de un actor complejo, cuyos contornos ideológicos aparecen difusos, y sobre el cual poco se ha indagado 9 . Nos detendremos específicamente en la descripción y análisis del proyecto diseñado para atender a la formación de las bases del movimiento. Si

después, responsabilizarían a los "grupos vanguardistas de la violencia armada" que la conciben como el único camino de transformación, del avance de las derechas en la región. CLAT, Informativo CLAT. Vocero del movimiento de los trabajadores comprometido con la liberación de los pueblos de América Latina, Año 2, Nº12, Caracas, abril 1977, 8, en IISH.

${ }^{6}$ Para un análisis de este proceso véase Patrick Pasture, Christian Trade Unionism in Europe since 1968. Tensions between identity and practice, Londres, Aldershot, 1994.

7 Véase Gerd-Rainer Horn y Emmanuel Gerard (eds.), Left Catholicism. Catholics and Society in Western Europe at the Point of Liberation 1943-1955, Lovaina, KADOC-Leuven University Press, 2001; Lex Heerma van Voss, Patrick Pasture y Jan De Maeyere (eds.), Between Cross and Class: Comparative Histories of Christian Labour in Europe 1840-2000, Bern, Peter Lang, 2005; Gerd-Rainer Horn, Western European Liberation Theology: The First Wave (1924-1959), Nueva York, Oxford University Press, 2008; y del mismo autor The Spirit of Vatican II. Western European Progressive Catholicism in the Long Sixties, Oxford, Oxford University Press, 2015.

${ }^{8}$ Robert Alexander, International Labor Organizations and Organized Labor in Latin America and the Caribbean. A History, California, ABC-CLIO, 2009, 224. Cabe destacar su proximidad -como asesor y consultor- con la AFL-CIO, en las antípodas de la corriente que aquí abordamos.

9 Se puede consultar: Efrén Córdova, "El neosindicalismo cristiano en la América Latina: CLASC", Revista de Ciencias Sociales, 12:2, 1968, 255-295; Michael Francis, "Revolutionary Labor in Latin America: the CLASC", Journal of Inter-American Studies, 10:4, 1968, 597-616; Gerhard Wahlers, Nace una alternativa, Miami, Saeta Ed., 1991. También se encuentran referencias en trabajos generales sobre el sindicalismo en América Latina: Julio Godio, Historia del movimiento obrero latinoamericano. Socialdemocracia, socialcristianismo y marxismo, 1930-1980, Caracas, Ed. Nueva Sociedad, 1985; Julio Godio y Achim Wachendorfer, "Las internacionales sindicales", Nueva Sociedad, 83, 1986, 81-88; Alexander, op. cit.; Daniel Parcero y Mario Morant, El sindicalismo argentino: de no alineado a la unidad global, Bs.As., CICCUS, 2016. 
desde años tempranos se otorgó una importancia sustancial a la participación de éstas en la imaginación, elaboración y ejecución del modelo de sociedad que debería suplantar al capitalista, el denominado Proceso Colectivo de Elaboración Ideológica (PCEI) constituye el mayor -y único en la época- esfuerzo por llevar ese deseo a una escala continental ${ }^{10}$.

\section{Guerra Fría latinoamericana, secularización y politización}

\section{De CLASC a CLAT: extendiendo el horizonte de representación}

Como mencionamos, la CLASC surgió en 1954 en Santiago de Chile, como una acción impulsada por la CISC destinada a promover el sindicalismo cristiano en la región ${ }^{11}$. Su proceso de conformación da cuenta tanto de una debilidad organizativa inicial como de la estrategia que se dieron para llegar a conformar un colectivo importante en términos cuanti y cualitativos; lo cual quedó plasmado cuando en 1971 pasan a llamarse Central Latinoamericana de Trabajadores (CLAT) ${ }^{12}$. Dicho cambio respondía a la decisión de ampliar su arco de representación más allá de identidades religiosas, preocupación que como vimos compartían con sus pares de la CMT. Sumado a ello, ya no se buscaba sólo a los trabajadores sindicalizados, sino que se apelaba a las organizaciones de pobladores, campesinos, a las mujeres, los jóvenes y al movimiento cooperativo ${ }^{13}$. Efectivamente, su mayor influencia estuvo entre los sectores campesinos y urbanos pobres de los países menos desarrollados; por lo que, si bien contó con representación en la mayoría de los países de la región, logró instalarse con mayor fuerza en Venezuela, Ecuador, República Dominicana, Colombia y otros países de la zona del Caribe. Si bien no se cuenta con datos precisos, se estima que para los años 1967-1968 la Confederación aglutinaba entre medio y un millón de adherentes y simpatizantes ${ }^{14}$. Llegó a ser la segunda organización sindical en la región después de la Organización Regional Interamericana de Trabajadores (ORIT) ${ }^{15}$-con quien se disputaba la influencia sobre las masas obreras no comunistas en la región ${ }^{16}$ - y la principal regional dentro de la $\mathrm{CMT}^{17}$.

Concordante con este proceso, hablarían de "Movimiento de Trabajadores", sujeto que era entendido de la siguiente manera:

\footnotetext{
10 Para este trabajo hemos consultado la prensa de la organización, libros, documentos y folletos publicados por su sello editorial, cuadernillos elaborados para los seminarios de formación e informes relativos a las actividades e instituciones educativas; disponibles en la biblioteca del IISH y en la Colección A. Vanistendael del Centro de Documentación e Investigación sobre Religión, Cultura y Sociedad de Lovaina (KADOC).

11 El carácter de afiliación a la misma fue muy heterogéneo, aglutinando, según los países, desde corrientes internas hasta sindicatos y federaciones nacionales. Incorporó a sectores que quedaron desperdigados a medida que se fue frustrando y desarticulando la Agrupación de Trabajadores Latinoamericanos Sindicalistas -ensayo peronista de organización regional no alineada-, ya que su orientación y propuestas eran similares. Véase la entrevista a Emilio Máspero en Parcero y Morant, op. cit., 61.

12 A su vez, desde 1966 había pasado a autorreferenciarse como Confederación Latinoamericana Sindical Cristiana, manteniendo la sigla CLASC.

${ }^{13}$ Ello llevó a algunos a definirla más como un "movimiento social de base proletaria o de sectores marginales" que como una confederación sindical. Córdova, op. cit., 257.

14 Según la propia organización, la cifra llegaría a los cinco millones, véase Emilio Máspero, "Latin America’s Labor Movement of Christian Democratic Orientation as an Instrument of Social Change", William D' Antonio y Fredrick Pike (eds.), Religion, Revolution, and Reform. New forces for change in Latin America, Nueva York, Praeger, 1964, 180.

${ }_{15}$ Miembro de la Confederación Internacional de Organizaciones Sindicales Libres (CIOSL).

16 En esta etapa la Confederación de Trabajadores de América Latina (CTAL) -afiliada a la Federación Sindical Mundial (FSM)- ya se encontraba muy debilitada.

17 Para 1968, América Latina representaba el 40\% de sus afiliados. CLASC, Vocero..., Año II, N²0, noviembre-diciembre, $1968,3$.
} 
La CLAT ha dado una definición del 'trabajador' que supera el concepto primitivo del 'obrerismo' y ciertas definiciones marxistas también unilaterales e incompletas, y no adecuadas para interpretar la típica y original situación de la clase trabajadora de América Latina. Para nosotros trabajador es toda persona cuya situación económica, jurídica, social, cultural, técnica y sicológica está ligada a una actividad profesional de ejecución subordinada y dependiente. Y también es trabajador toda persona cuyo único medio de subsistencia es su fuerza de trabajo -manual o intelectual- enajenada y apropiada al servicio del capital ${ }^{18}$.

En la misma tónica, reiteradas veces se enfatizó la idea de que el sindicalismo latinoamericano había sido hasta el momento más un producto de importación que resultado de la creatividad y experiencia de los trabajadores $\operatorname{mismos}^{19}$, situación que esta Central, argumentaban, vendría a resolver.

Provistos de estas definiciones amplias en términos teóricos y estratégicos, en el plano político y táctico la organización emprendió un camino de crecimiento cuantitativo, que cualitativamente debería ser apuntalado con claros posicionamientos político-ideológicos sobre el movedizo contexto en el cual actuaban y que los interpelaba. Si por un lado se encontraba imbuida en el aire de secularización y politización que atravesaba a sus organizaciones hermanas de la CMT, lo que diferenciaría a la CLASC/CLAT era el proceso de radicalidad abierto en América Latina, especialmente a partir de la Revolución Cubana. A pesar de su oposición y críticas al régimen castrista, el horizonte de posibilidad de transformación social que aquella abrió sin duda impregnó las prácticas y retórica de la Central como la de tantos otros actores del periodo-.

\section{Los Congresos y la profundización de las definiciones políticas}

Efectivamente, el tono confesional en las resoluciones emanadas de los primeros congresos como la moderación de las acciones que desplegaba, comenzaría a cambiar a partir de 1959. En este año tiene lugar en Quito el III Congreso Continental, en donde se señala a las estructuras capitalistas existentes como las generadoras de pobreza. Sería, pues, necesario asumir tareas políticas para superar dichas estructuras, lo que significaba salir del plano meramente reivindicativo en el cual se habían movido hasta el momento. Estas críticas se refuerzan aún más durante el IV Congreso (Caracas, 1962), sumando condenas concretas a los regímenes militares o pseudo-democráticos ${ }^{20}$. No olvidemos que un año antes se había lanzado la Alianza para el Progreso (ALPRO) como estrategia reformista de combate al avance del comunismo en la región, política que la CLASC condenaría, como a aquellas organizaciones sindicales pronorteamericanas -la ORIT- que la sostenían ${ }^{21}$.

El V Congreso que se lleva a cabo en Panamá en 1966, identificado ya desde su convocatoria como el congreso de las "nuevas dimensiones", avanza aún más en esta línea. A partir de aquí la CLASC fue reorganizada ${ }^{22}$, su sede se trasladó a Caracas y asumió como secretario general Emilio

18 CLAT, Vocero del movimiento de los trabajadores comprometidos con la liberación de los pueblos de América Latina, Año VI, N44, Caracas, octubre 1972, 8, en IISH.

19 “ No copiemos más! Es necesario crear...”, gritaba el secretario general en un encuentro latinoamericano de trabajadores bancarios. CLASC, Vocero..., Año V, N³7, septiembre 1971, 1 (resaltado en original).

20 A lo largo de los años y a través de su prensa, puede leerse la condena a la brutal dictadura de Duvalier en Haití y a la seudodemocracia de Barrientos en Bolivia, o la situación en República Dominicana, y posteriormente a las violentas dictaduras del Cono Sur, a las cuales denunció incansablemente.

21 Entre los corrimientos que pueden observarse en los posicionamientos de la organización, éste fue uno. Inicialmente el problema no fue tanto la ALPRO -cuyos objetivos compartían- sino su implementación por parte de los funcionarios norteamericanos intermedios. La adscripción a una "revolución democrática y cristiana", a una "revolución social con libertad", tenía puntos de contacto con la noción de "revolución pacífica" de su ideólogo, el presidente J.F. Kennedy. Emilio Máspero, El sindicalismo como instrumento de la revolución en América Latina, sin datos de edición [1963], 48 y 60-61.

22 Para una historia institucional exhaustiva véase Wahlers, op. cit. 
Máspero ${ }^{23}$, quien expresaba al interior de la confederación latinoamericana una línea más combativa, antiimperialista y tercermundista que la de los referentes democratacristianos chilenos hasta entonces al frente.

Unos años después, el VI Congreso de 1971 desarrollado en Bogotá no solo trajo el mencionado cambio en la denominación de la organización -por CLAT-, sino la explicitación del acelerado proceso de secularización y radicalización política ${ }^{24}$. Aunque la CLASC/CLAT nunca negó la filosofía social del cristianismo como principio inspirador, que hacía a una concepción integral del hombre y la sociedad, a partir de aquí sus metas ya no se presentarían en términos de "desarrollo solidario"25 sino de "liberación", proceso en el cual los trabajadores cumplían un rol fundamental. Ello iba en sintonía con planteos que pueden rastrearse con anterioridad al interior de la propia iglesia latinoamericana ${ }^{26}$. En ese mismo encuentro se esbozaron algunos lineamientos para la construcción de una sociedad de nuevo tipo -en principio no capitalista-. Se habla del "SOCIALISMO COMUNITARIO" como "una posible OPCION POLITICO-HISTORICA de la clase trabajadora para la nueva sociedad"27. Con inspiración en el humanismo cristiano, se concebía como la puesta del poder político y económico en manos de los y las trabajadores y el pueblo organizado.

En un contexto en que Estados Unidos intercalaba sus acciones contrainsurgentes con una avanzada batalla cultural28, la CLASC/CLAT compartió el sentimiento antiimperialista cada vez más marcado en la región ${ }^{29}$; condena que extendía a la Unión Soviética. Para la Central la contradicción entre Norte y Sur en términos de desarrollo prevalecía sobre aquella que oponía a Este y Oeste en términos de ideologías: "capitalismo o comunismo" -decían- no era más que un "dilema imperialista" 30. En esta línea abrazó un fuerte tercermundismo, que enfatizaba y promovía la existencia de una identidad común latinoamericana, buscando la construcción de la Patria Grande.

Siempre despojada de atributos confesionales, esta tónica revolucionaria se apaciguaría hacia el VII Congreso (San José de Costa Rica, 1977). En un contexto de avanzada de lo que identifican como el "fascismo capitalista" en la región, el grito de liberación será suplantado por un llamado a conquistar la "libertad y defensa de los derechos humanos" de los trabajadores, y la condena de la explotación y la opresión toma formas más concretas de denuncia al empeoramiento de las condiciones de vida y trabajo, salariales, etc. ${ }^{31} \mathrm{Al}$ tiempo que se definían como una "organización de Clase, de Masas y de

\footnotetext{
${ }^{23}$ Dirigente sindical argentino (1927-2000) formado en distintos centros jesuitas; integró la Juventud Obrera Católica (JOC) y en 1955 fundó Acción Sindical Argentina. Desde 1966 y por 34 años fue secretario general de la CLASC/CLAT. Desde 1967 también ocupó la vicepresidencia de la CMT.

${ }^{24} \mathrm{Al}$ punto que Wahlers ha caracterizado la etapa abierta a partir de aquí como la "fase ultraizquierdista" de la organización. Véase Wahlers, op. cit, capítulo V.

${ }^{25}$ Entendido como un "desarrollo a la medida del hombre, de todo el hombre y de todos los hombres". CLASC, Vocero..., Año III, N²4, junio 1969, 2. Aquí se observa la influencia de la Teología del Desarrollo del dominico francés L.J. Lebret. Éste fue muy influyente en Brasil, sobre todo en obispos como Hélder Câmara, a quienes la CLASC leía -de hecho van a proponerlo como candidato al premio nobel de la paz 1970-. Además, su "desarrollo integral del hombre" impregnó el Concilio Vaticano II -donde de la mano del brasilero se desempeñó como especialista-. Véase Silva Gotay, op. cit., 41, 52-53; Michael Löwy, Guerra de dioses: religión y politica en América Latina, México, Siglo XXI, 1999, 195.

26 Tal como diría el brasilero Câmara, la palabra desarrollo "en la que creíamos tanto ... decepcionó nuestras esperanzas. Hoy preferimos hablar de liberación”, citado en Löwy, op. cit., 197. Véase Enrique Dussel, Historia de la iglesia en América Latina: medio milenio de coloniaje y liberación (1492-1992), Madrid, Mundo Negro-Esquila Misional, 1992.

${ }_{27}$ CLASC, Vocero..., Año V, No38, noviembre 1971, 14 (resaltado en original).

${ }_{28}$ Calandra Benedetta y Marina Franco (eds.), La guerra fría cultura en América Latina, Bs As, Biblos, 2012.

29 Se plasmó en un férreo repudio a la guerra de Vietnam y a la intervención estadounidense en República Dominicana, la condena de su aval al golpe de 1964 en Brasil, el reclamo por la independencia de Puerto Rico. Asimismo, cuestionó la reproducción de las desigualdades regionales implícitas, por ejemplo, en organismos como la Organización de Estados Americanos.

${ }^{30}$ CLAT, La CLAT en la encrucijada. Informe político y de orientación presentado por Emilio Máspero, secretario general de la CLAT, a nombre del Comité Ejecutivo Latinoamericano, ante el VII Congreso de la CLAT, Caracas, FLACPO, 1978, 65, en IISH.

31 CLAT, Informativo CLAT..., Año 2, Nº18, octubre 1977, 11.
} 
Confrontación" 32 , se convocaba al encuentro de Costa Rica bajo la consigna "Por la libertad y la democracia hacia la nueva sociedad de los trabajadores"33. En esta línea, si a diferencia de la ORIT la CLASC/CLAT no había presentado hasta aquí posiciones anticomunistas en términos genéricos, a partir de 1976-77 se registran virulentas denuncias al "marxismo-leninismo", equiparándolo, en sus efectos negativos sobre los trabajadores y sus organizaciones, al "totalitarismo de derecha" 34 .

Estas definiciones obligan a una mirada no evolutiva ni estática de la CLASC/CLAT y a su vez, a profundizar en los sentidos que otorgó a términos tan propios de la época -y por lo tanto opacos para definir su orientación ideológica- como revolución o liberación ${ }^{35}$.

\section{Concientización y poder}

A lo largo de estos años se insistió sobre dos ideas/procesos: la necesidad de "construir el poder organizado de los trabajadores"36 y de proyectar una "nueva sociedad". Esta dinámica requería, además, de un "hombre nuevo" ${ }^{37}$. Y nada de esto podría ser realizado sin atender a los aspectos ideológicoculturales de la lucha, dado que "dentro del movimiento obrero hay que operar una real revolución cultural que nos libere definitivamente de la conciencia mágica e ingenua y plasme en todos los trabajadores y en todos sus dirigentes una profunda y lúcida conciencia crítica y politica" 38 .

Para llevar a cabo esta empresa contó con su propio sello editorial, FLACPO (Fondo Latinoamericano de Cultura Popular). Otra importante herramienta de concientización fue la prensa. Entre 1967 y fines de 1971 salió CLASC. Vocero del sindicalismo revolucionario en América Latina, posteriormente denominada CLAT. Vocero del movimiento de los trabajadores comprometidos con la liberación de los pueblos de América Latina. A partir de 1975 se produjo una reorientación en la política de publicaciones, por lo que desde abril de 1976 apareció Informativo CLAT, y a fines de ese año comenzó a editarse trimestralmente la Revista de orientación ideológica y política, pensada como un instrumento para profundizar la reflexión doctrinaria y estratégica.

Por otro lado, en la consecución de dicha meta las tareas de formación sistematizada cobraban centralidad. En su concepción, la formación siempre estuvo orientada hacia el fortalecimiento de la organización y de la acción político-gremial, entendida la primera como "una dimensión complementaria" 39 de las otras dos. A la vez, la acción fue siempre considerada promotora de concientización: se buscaba "profundizar las reivindicaciones para acentuar la movilización y la lucha sindical, como vehículo de concientización de los trabajadores" 40 . Uno de sus lemas resumía esta mirada dialéctica: "Queremos una acción y organización que forme y una formación para la acción y la organización" ${ }^{4}$. Vale decir, teoría y práctica, reflexión y acción eran entendidos como estadios interrelacionados y complementarios de un mismo proceso, aunque era la última la que jugaba un papel

\footnotetext{
32 CLAT, Sólo el poder detiene al poder. Acuerdos del VII Congreso sobre programa de reivindicaciones, de organización y acción, sobre acción profesional y sobre politica de organización de cuadros y formación global, Caracas, FLACPO, 1978, 178, en IISH.

33 CLAT, Informativo CLAT..., Año 2, №19, noviembre 1977, 1.

34 CLAT, Informativo CLAT..., Año 2, N¹2, abril 1977, 8-9.

35 Córdova ha definido el contenido ideológico de la CLASC/CLAT como una mezcla de socialismo democrático y humanismo revolucionario. Por su parte, Godio sostiene que ésta definió "su proyecto sindical tercermundista, con una amalgama de ideas que han conducido a la formulación del 'socialismo comunitario' autogestionario". Respectivamente, Córdova, op. cit., 258 y Godio, op. cit., 261.

36 CLAT, Vocero..., Año VIII, No64, julio-agosto 1974, 2.

${ }^{37}$ Las referencias eran al Che Guevara y al Evangelio. CLAT, Vocero..., Año VI, Nº44, octubre 1972, 8.

38 CLASC, Vocero..., Año IV, No31, julio-agosto 1970, 1 (resaltado nuestro). Nótese la resignificación del pedagogo Paulo Freire, quien reconoce tres tipos de conciencia: mágica, ingenua y crítica.

39 CLAT, Sólo el poder..., op. cit., 222.

40 CLASC, Vocero..., Año I, No10, enero 1968, 4.

${ }^{41}$ CLAT, Sólo el poder..., op. cit., 222.
} 
decisivo. Nada de esto, además, podía realizarse si no era acompañado con una "mística de liberación, de revolución, de promoción humana" 42 .

\section{Formación para construir la "nueva sociedad"}

\section{El andamiaje de la "revolución cultural"}

A los fines de potenciar el proceso de racionalización de la reflexión que los propios trabajadores y trabajadoras realizaban a partir y en el marco de su acción, la CLASC/CLAT diseñó una compleja estructura encargada de brindar la formación ${ }^{43}$.

Hasta 1974 en que se inauguró la Universidad de los Trabajadores de América Latina (UTAL), el principal centro de formación de la CLASC fue el Instituto Latinoamericano de Estudios Sociales 'Humberto Valdés' (ILATES), cuyo funcionamiento comenzó a fines de 1966. Ambos tuvieron sede en Caracas y su director fue José de Jesús Plana ${ }^{44}$. De forma vinculada existían cuatro institutos de alcance regional, como también numerosos centros nacionales en quienes recaían las tareas de formación de base. El ILATES -y posteriormente la UTAL- realizaba la asistencia técnica a los centros mencionados y a los departamentos o secretarías de educación de los sindicatos afiliados; pero además organizaba seminarios de alcance latinoamericano destinados a dirigentes sindicales, los que se desarrollaban en su sede. Una vez creada la UTAL, se complementaron las actividades de formación con aquellas de investigación, documentación y divulgación a través de la creación de tres organismos especializados.

Un dato que reafirma el interés de la Central por la cuestión educativa es que destinó aproximadamente el setenta por ciento de sus recursos a la formación y entrenamiento de dirigentes, activistas y miembros ${ }^{45}$. El sostén económico de estas actividades se derivaba fundamentalmente de la ayuda internacional y del autofinanciamiento -a través del pago de una matrícula (equivalente a un día de salario)-46.

Los encargados de pensar la formación dentro de la Confederación distinguieron entre una Formación Abierta y otra Cerrada. La primera consistía en una educación inicial para los y las trabajadores de base, era más flexible en términos de disciplina y periodicidad, y podía realizarse en el marco de una reunión, asamblea, cursillo, lectura grupal de libros, teatro, cine foro, etc. Como parte de ésta se desarrolló de modo simultáneo y a escala regional el mencionado PCEI, experiencia de la que hablaremos a continuación. La Formación Cerrada en cambio, estaba dirigida a militantes y dirigentes, tenía un contenido especializado y superior, que apuntaba al entrenamiento ideológico y político de los cuadros de distinto nivel, y debía realizarse bajo el régimen de internado.

\footnotetext{
42 CLASC, Formación de trabajadores para América Latina. Manual de Formación por el grupo responsable de formación de la CLASC, Caracas, FLACPO, 1971, prólogo de Emilio Máspero, 9.

43 Para una descripción y análisis de los contenidos y metodologías implementados a lo largo de los años y en los distintos niveles de formación, véase Gabriela Scodeller, "Political Training and Social Change in the 1960s and 1970s: the Educational Activities of the Latin American Central of Workers (CLAT)", ILWCH, 90, 2016, 93-110. Para referencias sobre el proceso de formación durante la etapa post-dictatorial en el Cono Sur, véase Mónica Gordillo, "Activismo sindical transnacional en el Cono Sur: algunas experiencias", Clepsidra. Revista Interdisciplinaria de Estudios sobre Memoria, 4:7, 2017, 68-83.

44 Cabe señalar que éste también se desempeñó como consultor en materias de educación obrera para la Organización Internacional del Trabajo (OIT); lo cual es indicador de los circuitos transnacionales en los que participaba la CLAT. CLASC, Vocero..., Año III, N²9, enero-febrero 1970, 6.

45 Alexander, op. cit., 210-211. Según Francis, este gasto sólo habría representado el cincuenta por ciento de su presupuesto. Francis, op. cit., 603.

46 A pesar de insistir en la importancia del autofinanciamiento -se organizaba anualmente una campaña dirigida a recaudar fondos entre sus bases obreras y campesinas-, ello fue difícil de lograr dada la escasa capacidad financiera de las organizaciones afiliadas.
} 
En sus primeros quince años de vida, la CLASC habría realizado unos doscientos seminarios y cursos latinoamericanos y más de cinco mil eventos de formación en los distintos países ${ }^{47}$. A modo ilustrativo, entre 1965 y 1967 habrían pasado unos 35 mil trabajadores, activistas y dirigentes de distinto nivel por este último tipo de actividades ${ }^{48}$, y sólo en 1968 unos 30 mill4. Asistieron a los 41 eventos con internado organizados por el ILATES entre 1966 y 19721.421 cuadros de distinto nivel -entre quienes cabe señalar que la participación femenina no alcanzaba al ocho por ciento-. Poco más de la mitad tenían estudios secundarios, y sus edades oscilaban entre los 20 y los 40 años. El ochenta y dos por ciento provenía de ámbitos urbanos y en términos regionales, casi la mitad de países de la región Andina ${ }^{50}$. Entre 1974 y 1983, ya con la UTAL en marcha, se realizaron 133 eventos con internado, de los que participaron 5.003 dirigentes ${ }^{51}$.

Los encuentros latinoamericanos se organizaban según rama de actividad, por región, nucleando a quienes ocupasen cargos similares en las secretarías de los sindicatos, o por sectores de población. Se trataban las problemáticas particulares y elaboraban una serie de propuestas en función de sus necesidades concretas; pero también se abordaban temáticas comunes y más generales. Este tipo de encuentros se desarrollaban a lo largo de unas cuatro-seis semanas en la sede del ILATES. Se implementaba una metodología de Curso-Seminario, que combinaba exposiciones de docentes con técnicas grupales de trabajo. Los cuadernillos utilizados desarrollaban los temas de modo sintético, con un lenguaje claro y sencillo, cumpliendo la doble función de apuntes de clase y manual-guía para la acción.

Desde septiembre de 1975, en una línea focalizada en la formación de cuadros de conducción, se inauguró una nueva serie de eventos de larga duración. Se denominaron Seminarios de Formación Superior de Conducción Global Política y Estratégica, y buscaban dotar "de una cosmovisión Doctrinaria-Ideológica, Técnica-Científica, Estratégica y Política ... que ponga en condiciones a los participantes para conducir a partir de sus propias realidades..." los destinos de sus organizaciones ${ }^{52}$. Estos seminarios tenían una duración de tres meses, aunque eran aún más extensos, puesto que, al modo de cursos por correspondencia, preveían una extensa etapa de preparación previa. Como veremos, esta línea de formación de cuadros de conducción se profundizará a partir de 197753 .

\section{Reflexión en, por y para la acción ${ }^{54}$}

Sosteniendo dicho andamiaje existía una profunda reflexión político-pedagógica. Esta perspectiva fue socializada por medio de un manual de formación para educadores que se editó en 197155. Escrito por Rodolfo Efrén Romero Garcete ${ }^{56}$ aunque basado en la elaboración y discusión colectiva del Equipo ILATES ${ }^{57}$, a la vez recogía muchos elementos del trabajo grupal llevado a cabo

\footnotetext{
47 CLASC, Formación de trabajadores..., op. cit., 151.

48 CLASC, Vocero..., Año I, Nº7, octubre 1967, 3.

49 CLASC, Vocero..., Año II, No21, enero-febrero 1969, 3.

50 CLAT, Proyecto UTAL, Volumen 2, Anexos: III - Resumen estadístico de los eventos realizados por el ILATES desde noviembre de 1966 a diciembre de 1972, en KADOC BE/942855/757/1047.

51 UTAL, Diez años de la UTAL: Algunos aspectos evaluativos. San Antonio de los Altos, 30/04/1984, 10, en KADOC $\mathrm{BE} / 942855 / 757 / 1047$.

52 CLAT, Vocero..., Año I, Nº1, Caracas, abril 1976, 10.

53 La modificación coincide con la reorientación editorial mencionada. Volveremos sobre esto ya que el cambio de énfasis en la formación fue en parte consecuencia del balance realizado sobre el PCEI.

${ }^{54}$ CLASC, Formación de trabajadores..., op. cit., 109.

55 Idem.

56 Entonces ex Sub-Director del ILATES y Director del Instituto de Capacitación Social del Sur (INCASUR).

57 Integrado por: José de Jesús Plana, Víctor Durán, Oscar Martínez, Acacia Fernández de Máspero, Gerardo Inehausti, entre otros. Los integrantes del equipo de formadores de la CLASC/CLAT se definían como militantes del movimiento obrero y
} 
durante los distintos Cursos-Seminarios organizados para los y las Responsables de Formación que se realizaron anualmente desde $1965^{58}$.

En el mencionado manual se describe cómo es que el adulto-trabajador elabora y construye conocimientos y, por tanto, como debe ser pensada y planificada una formación sistematizada, que vaya en paralelo con el proceso de transformación y liberación tanto individual como social. En este sentido, la función de la formación es: "SITUAR al trabajador en su REALIDAD CONCRETA, en tiempo y espacio. INTERPRETAR la realidad conforme a los INTERESES Y VALORES en juego. COMPROMETER al trabajador para TRANSFORMAR LA REALIDAD"59. Es durante el segundo momento que el trabajador va desarrollando su "juicio crítico y político", siendo capaz de ofrecer "su interpretación" en relación con aquella realidad inicial. En el tercer momento se busca en cambio el "compromiso militante". De esta forma se desarrolla respectivamente el "ser, pensar y actuar" de dicho "hombre militante".

Ello se vincula con los tres elementos del proceso formativo, respectivamente: "información, reflexión, acción”. La reflexión, como momento de análisis y juicio crítico de la información produce la toma de conciencia, aspecto necesario para el compromiso y la acción. A su vez, la acción proporciona nuevos datos, que serán objeto de nuevas reflexiones, concluyendo en nuevas acciones. Cómo se ve, estos elementos vienen siempre engarzados los unos a los otros dialécticamente, y la estrecha interacción entre ellos hace que el circuito pueda encenderse por cualquiera de sus partes. Ello hacía que, tal como afirmaban, "tengamos una concepción dinámica de la organización, una concepción dialéctica de la acción y una concepción militante de la formación" ${ }^{0}$. Lo anterior no es sino la elaboración teórico-política, pedagógica, de lo que en el quehacer concreto era esquematizado bajo la tríada: "VER, JUZGAR, ACTUAR", y que veremos plasmado de modo más contundente en la planificación e implementación del proyecto de formación para las bases del movimiento conocido como PCEI.

Proveniente de la "metodología de revisión de vida" creada en los años veinte por el sacerdote belga Joseph Cardijn -fundador de la Juventud Obrera Cristiana (JOC)-, esta tradición impregnó la concepción pedagógica de la CLASC/CLAT ${ }^{61}$. Se entrecruzaba y complementaba con insumos procedentes de la pedagogía crítica latinoamericana, la que sin embargo estuvo presente en sus propuestas educativas de un modo menos explícito. Pero si bien los textos no suelen traer referencias

técnicos de la organización sindical (especializados en formación de adultos), cuyo "trabajo es UNA FUNCION TECNICA realizada con SENTIDO MILITANTE”. Ibid, 248 (resaltado en original). Es interesante señalar, sin embargo, que la mayoría de ellos -O al menos los principales referentes- provienen de una trayectoria de militancia sindical jocista en el marco de la cual se han desempeñado como dirigentes y a la vez han asumido tareas de formación y estudio. Los casos más significativos son los de José de Jesús Plana y Rodolfo Romero.

58 Para un análisis en profundidad del mencionado manual como de los encuentros destinados a la formación de formadores, véase Scodeller, op. cit.

59 CLASC, Formación de trabajadores..., op. cit., 67 (resaltado en original).

${ }^{60} \mathrm{Ibid}, 33$.

${ }^{61}$ Cabe señalar que la misma tuvo una amplia circulación a partir de su incorporación en la encíclica Mater et Magistra (1961) por parte del Papa Juan XXIII; siendo luego recomendada también por el Concilio Vaticano II y la Conferencia de Obispos Latinoamericanos en Medellín. Recordemos también que los principales cuadros de la CLASC provenían de experiencias jocistas. Parcero y Morant, op. cit., 63. 
bibliográficas, se encuentran citas de algunos textos de Paulo Freire ${ }^{62}$, y también menciones a su obra en disertaciones de invitados ${ }^{63} \mathrm{o}$ discursos de los propios dirigentes ${ }^{64}$.

En esta "pedagogía de la transformación" el trabajador, "como SUJETO, se convierte en AGENTE DINAMICO que construye y realiza personal y comunitariamente el proceso de formación" 65 . En esta línea fue pensado el desarrollo del PCEI, otorgando una fuerte responsabilidad a los propios sujetos objeto de la formación.

\section{El Proceso Colectivo de Elaboración Ideológica}

\section{E1 PCEI como proyecto}

Dentro del esquema de formación descripto, las actividades pensadas para las bases del movimiento ocuparon un lugar estratégico. Dado que la CLAT se movía por regiones y entre sectores en los que el analfabetismo o un muy bajo nivel de instrucción era un obstáculo importante, apeló a distintos formatos a los fines de circular su mensaje. La gráfica política fue uno de ellos, utilizada en afiches donde con potentes imágenes transmitían sus consignas, conmemoraban fechas significativas o llamaban a movilizarse. La oralidad fue otro recurso utilizado, como muestra la combativa letra del "Himno de los Trabajadores de América Latina"66. Para generar espacios de formación y debate menos estructurados también se promovió la realización de cine-foros y el teatro popular.

De modo mucho más sistematizado, a partir de 1973 se dio inicio a lo que se denominó Proceso Colectivo de Elaboración Ideológica (PCEI). En parte para avanzar en la construcción de "un verdadero sindicalismo militante y de masas, un sindicalismo renovado desde las bases mismas" 67 . Pero fundamentalmente, para contribuir a la elaboración del modelo de nueva sociedad que se había propuesto la CLAT, tarea que, como hemos visto, requería ser realizada "de forma consciente". Partiendo de un diagnóstico más general por el cual el capitalismo estaba librando una fuerte batalla en el frente cultural, y que era contra la "enajenación" en dicho ámbito que la Central debía profundizar su accionar, el PCEI fue entendido como una "revolución cultural" cuyo propósito era

62 CLASC-DELAT, Los problemas de la educación en Latinoamérica, sin lugar, 1968. Aquí la referencia a 'La educación como práctica de la libertad' es contemporánea al año de su publicación. Entre 1969 y 1972 (según los lugares y traducciones) circulaba 'Pedagogía del oprimido', texto que aparece sugerido para trabajar el Tema 'Educación' del Ciclo I y en la 'Guía para el Animador’ del Ciclo II del PCEI.

${ }^{63}$ A fines de 1969 Paulo de Tarso Santos, ex ministro de educación de João Goulart (1962-64), expuso sobre "los nuevos procedimientos incorporados al método de alfabetización y concientización de Paulo Freire, y su aplicación para la organización del pueblo". CLASC, Vocero... Año III, N²7, septiembre-octubre 1969, 10.

${ }^{64}$ Por ejemplo, en el marco de la I Conferencia de Trabajadores de la Educación y la Cultura de América Central y del Caribe (Curazao, abril de 1974), E. Máspero se refirió a la obra del "amigo Paulo Freire" en Brasil, "un hombre cuyas obras seguramente conocen todos ustedes". CLAT, Una nueva educación en la perspectiva del Movimiento de los Trabajadores, Caracas, 1974, 9 y 8 respectivamente, en KADOC BE/942855/757/1041. Cabe considerar que el pedagogo no fue patrimonio de una corriente en particular sino referencia para un conjunto amplio y heterogéneo de grupos, en especial dentro del mundo católico. Como señala Rodríguez, la lectura y amplia circulación de la obra de Freire por América Latina debió mucho a la labor de la democracia cristiana. Lidia Rodríguez, Paulo Freire. Una biografía intelectual. Surgimiento y maduración de la pedagogía del oprimido, Buenos Aires, Editorial Colihue, 2015, 102. Inclusive, la apuesta por una "educación liberadora" presente en el Documento final del encuentro de 1968 del CELAM refleja su influencia, no sólo en los círculos de base.

65 CLASC, Formación de trabajadores..., op. cit., 113 (resaltado en original).

${ }^{66}$ Éste fue grabado en discos y puesto a la venta como modo de contribuir al autofinanciamiento de la organización. Puede leerse completo en Gabriela Scodeller, "Sources for Latin American Research at the International Institute of Social History. CLASC/CLAT”, ERLACS, 98, 2015, 99-104.

${ }^{67}$ CLAT, Vocero..., Año VII, N51, junio 1973, 8; Año VIII, No58-59, enero-febrero 1974, 13. 
ir echando las bases de una nueva cultura de los trabajadores, de una clara y sólida capacidad de autonomía de pensamiento, de decisión y de acción de los trabajadores y sus organizaciones, para aumentar en forma creciente los niveles de la conciencia crítica y política, de la conciencia de clase de los trabajadores: para que la clase trabajadora organizada se constituya en el sujeto histórico de los grandes procesos de liberación popular, nacional y latinoamericana ${ }^{68}$.

El PCEI fue resultado de las discusiones del VI Congreso de 1971. Finalizado éste, se daba inicio a un proceso que culminaría en el siguiente Congreso con la discusión y aprobación de lo elaborado en el ínterin. Organizativamente se estructuró de la siguiente manera. Estuvo coordinado de manera centralizada por una Comisión Política Latinoamericana (CPL), responsable de la orientación ideológico-estratégica que debía seguir todo el proceso; mientras que los encargados de su ejecución eran los Institutos o Secretarías de formación nacionales. La formulación de contenidos, metodologías y materiales didácticos estuvo en manos del ILATES primero y de la UTAL después ${ }^{69}$.

Sin embargo, el desarrollo de todo el proyecto se basaba en los Círculos de Estudio, grupos de no más de 10 trabajadores guiados por un Animador. Tal fue su relevancia que uno de los tres instructivos escritos para pautar su funcionamiento se dedicó enteramente al tema ${ }^{70}$. También fueron numerosas las notas en la prensa dedicadas a explicar su funcionamiento e importancia, donde en tono de arenga decían: "No se trata de quedarse a solas con su pensamiento: hay que pensar y reflexionar en forma colectiva y comunitaria: LOS CIRCULOS DE ESTUDIOS SON LA SOLUCION MAS SENCILLA Y EFECTIVA. Transformémonos en sembradores y animadores de círculos de estudio"71. Según la propia CLAT, se habrían formado mil círculos en toda América Latina, aunque la meta era duplicar dicha cifra, llegando a los 20.000 afiliados hacia el final del proceso, en 197772.

Por su parte, el animador cumplía un rol central, ya que era en quien recaía la responsabilidad de garantizar la continuidad del proceso del círculo: "es el que le da vida, movimiento al círculo de estudios". Por ello es que "deben ser convenientemente preparados, dándoles mayor información y conocimiento"73. Era, además, un eslabón fundamental en la comunicación entre bases y cúpulas. Cada animador debía producir informes de lo reflexionado en su círculo, en base a los que posteriormente la CPL elaboraría un Informe general. Esta dinámica estaba mediada por los centros nacionales de formación, los que debían garantizar la doble vía de diálogo (distribución del material y recopilación de las discusiones de los círculos). Se esperaba que a través de esta "reflexión colectiva, crítica y creativa", los y las trabajadores "aporten a su vez, a la CLAT, una mayor profundidad y precisión en todo esto; nuevas ideas, nuevas inquietudes, nuevas perspectivas, nuevas fórmulas junto con los necesarios correctivos" 74 .

La programación original estuvo organizada en cinco etapas de trabajo, se desarrollaría de manera simultánea en los distintos países y con los mismos contenidos. La primera fue de preparación. A lo largo de 8 meses debían montarse las estructuras organizativas y de Formación Abierta en cada país, elaborar los instructivos y materiales didácticos (para el primer Ciclo), difundir el PCEI y su

\footnotetext{
${ }^{68}$ CLAT, Vocero..., Año VI, No 48, marzo 1973, 2 (resaltado en original). Discurso de E. Máspero en el III Encuentro Latinoamericano de Responsables de Formación de la CLAT.

${ }^{69}$ En concordancia con la prédica de la Central sobre el autofinanciamiento, se buscó que el PCEI se sostuviese a través del aporte militante. Estimando que la inversión realizada hasta la puesta en marcha del Ciclo I había sido de diez mil dólares, se solicitó la donación de un dólar a cada trabajador que se incorporase.

70 Véase Comisión Política Latinoamericana (CPL), Instructivo para la realización del Círculo de Estudios. Instructivo $\mathrm{N}^{\circ} \mathrm{III}$, sin datos de edición [Caracas, fines de 1972], en KADOC BE/942855/757/1043.

${ }^{71}$ CLAT, Vocero..., Año VI, N 48 , marzo 1973, 5 (resaltado en original).

72 CLAT, Vocero..., Año VIII, Nº3, junio 1974, 2.

${ }_{73}$ CLAT, Vocero..., Año VII, N51, junio 1973, 8 (resaltado en original).

${ }^{74}$ CLAT, Proceso Colectivo de Elaboración Ideológica. Ciclo II: Aportes de la CLAT al movimiento de los trabajadores, Venezuela, FLACPO, sin fecha, Guía para el animador, 4, en IISH.
} 
necesidad, iniciar el entrenamiento de los animadores y realizar un seminario latinoamericano para responsables de formación. A partir de allí, en cuatro Ciclos se desarrollarían los distintos contenidos, cuyos títulos eran: Aportes históricos de la CLAT para la elaboración de un humanismo integral; Diagnóstico de la realidad nacional, latinoamericana y mundial; La construcción del poder organizado de los trabajadores; y Proyecto histórico de nueva sociedad. A nivel de cuadros de dirección, el PCEI no sólo sería acompañado por los seminarios destinados a los responsables del área de formación denominados Encuentro Seminario Latinoamericano para Responsables de la Formación y del Proceso Ideológico de la CLAT-, sino también por Seminarios Ideológicos sobre temáticas específicas, que debían brindar insumos para el trabajo en los círculos. Como veremos, este diagrama inicial sufrió fuertes modificaciones.

Tal como estaba planificado, durante la etapa preparatoria ${ }^{75}$ se inició una "campaña de información y animación" para crear las condiciones subjetivas de participación, se conformaron las comisiones políticas nacionales y los círculos de estudio, y se preparó a los animadores. Sin embargo, la dinámica posterior presentó sus dificultades, fundamentalmente en lo que concierne a la conformación o sostenimiento de los círculos. Por ello, de los ciclos programados sólo se realizaron dos: el primero inicialmente pautado para julio- inició en noviembre de 1973 y un segundo lo hizo en enero de 1975. Como resultado de la evaluación del primero, además, este último incorporó también la dinámica de Jornadas mensuales ${ }^{76}$.

\section{Contenidos y metodología}

Entre los materiales producidos para el PCEI, destacan una serie de cuadernillos elaborados para cada uno de estos ciclos ${ }^{77}$. Tenían la función de dar unidad y coherencia al proceso en las distintas regiones. Fueron editados por la CPL bajo la dirección de los responsables de la implementación de cada Ciclo, Oscar Martínez y Ricardo Reyes respectivamente, ambos del Equipo ILATES. En términos más generales, cabe destacar que fueron los únicos materiales diseñados de modo centralizado para los y las trabajadores de base del movimiento ${ }^{78}$. El proceso de aprendizaje se fundaba en la mencionada técnica del “ver-juzgar-actuar". Por cada Ciclo se contaba con una 'Guía para el animador' -con orientaciones tanto didácticas como políticas- y guías para el participante según los distintos ejes trabajados.

La guía para el animador funcionaba como un modelo preciso, pautando desde las "ideas fuerza" que éste debía enfatizar, hasta las dinámicas, instrumentos y los tiempos de trabajo, e inclusive el modo en que debía ser realizado el informe ${ }^{79}$. Por su parte, los participantes contaban con un cuadernillo para cada una de las temáticas abordadas. El primer Ciclo estuvo dedicado al diagnóstico de la realidad nacional, latinoamericana y mundial, y el segundo a discutir los aportes de la CLAT al movimiento de los trabajadores. Los temas del primero fueron quince y los del segundo ocho. Cada folleto se

\footnotetext{
${ }^{75}$ Comenzó en noviembre de 1971 -debería haber iniciado inmediatamente de concluido el VI Congreso-.

76 Según Ricardo Reyes (responsable de la implementación del PCEI en esta etapa), el segundo ciclo se habría desarrollado solo a través de Jornadas, donde unos 40 participantes a lo largo de todo un día abordaban dos temas. INES Venezuela, Primer Seminario Nacional de Actualización Ideológica, "5 Tema: Proceso Colectivo de Elaboración Ideológica”, Caracas, Julio 1975, 7, en KADOC BE/942855/757/1043.

77 CLAT, PCEI, Ciclo I... y Ciclo II..., op. cit.

78 Tanto la prensa como otros documentos editados tenían por destinatario a dirigentes y militantes. Era una política de la Central que éstos elaborasen sus propias publicaciones, las que debían estar adaptadas a los lenguajes y características de cada lugar, dada la diversidad de situaciones existente en América Latina. CLASC, Vocero..., Año IV, No34, noviembre-diciembre 1970, 10.

79 Sin embargo, en la Guía del Ciclo I aclaraban que "La reflexión ES UN CAMINO A RECORRER y el hecho de caminar supone formulaciones menos perfectas pero más vivas a fin de contrastarlas con la realidad”. CLAT, PCEI, Ciclo I..., op. cit., Guía para el animador, 7.
} 
componía de textos breves escritos en un lenguaje simple, acompañados con dibujos, caricaturas o fotografías. Las lecturas ofrecen desde documentos de la CLAT hasta cifras generales sobre los temas tratados, o desarrollos más conceptuales y teóricos de los procesos analizados; además se sugería a los animadores contar con mapas, gráficos, fotografías o datos específicos sobre su región, que ilustrasen más en detalle los distintos temas. Siguiendo el esquema de la encuesta jocista ${ }^{80}$, cada uno de los tres momentos iba acompañado por una extensa serie de preguntas que articulaban la comprensión de los materiales en la situación, contexto y experiencia del trabajador/a. Se sugería que la lectura de los folletos fuese realizada previamente, a fin de destinar el tiempo de la reunión del círculo (unas dos horas aproximadamente) para trabajar en base al cuestionario formulado al inicio del mismo.

Se apuntaba a una dinámica dialéctica de elaboración colectiva. Para ello, la CPL explicaba a los animadores que: "la información más valiosa e importante es la aportada por los propios participantes a partir de su experiencia personal... Sin embargo, esta información es orientada por los documentos de trabajo que se recomienda usar" 81 . En este sentido, que cada cuadernillo partiera de preguntas que invitaban a la reflexión de los y las miembros del círculo garantizaba la recuperación de saberes, a la vez que existía una clara definición ideológica para cada uno de los temas a discutir: no sólo a través de los textos seleccionados, sino en las directivas que se daba a los animadores respecto de las ideas que debían ser enfatizadas durante el desarrollo de cada contenido.

Cabe remarcar las enormes similitudes existentes entre el diseño del PCEI y el método de la JOC. Recordemos que los Círculos de estudio, grupos de no más de 12 personas que se reunían semanalmente para estudiar distintas problemáticas y prepararse para la acción, eran el embrión organizativo de la JOC. Allí se llevaba a cabo la "encuesta" bajo la guía de un sacerdote-asesor, quien debía elaborar "un informe que se eleva a la Federación, con los cuales se pensaba formar un archivo que sirviera para detectar los nuevos problemas que fueran surgiendo en el mundo obrero" 82 . Lo que se puede observar en el caso de la CLAT es la misma estructura de funcionamiento, aunque imbuida de una concepción secularizada del mundo. Es decir, aunque se recuperase el método de trabajo tradicional jocista, la reapropiación de la CLAT contenía diferencias de sentido. Por un lado, ya no era la reflexión bíblica la fuente del "juzgar" sino la propia realidad sociocultural del/la participante, entrando a jugar la influencia del pedagogo brasilero ${ }^{83}$. Por otro, la escala en que este método pretendía ser aplicado, y de un modo centralizado, también suponía una variación sobre la concepción original.

En cuanto a los contenidos desarrollados, a lo largo del Ciclo I los cuadernillos versaron sobre los siguientes temas: El trabajador y: su medio; los recursos naturales; el empleo y desempleo; la situación económica; la alimentación; la seguridad social; la vivienda; la educación; la empresa; la reforma agraria; la industrialización; la política; la integración de América Latina; sus organizaciones; el tercer mundo. Para el Ciclo II los títulos elegidos fueron: Persona - Familia - Igualdad; Trabajo; Empresa - Propiedad - Economía; Técnica - Cultura - Educación; Política - Democracia; Desarrollo Planificación - Integración; Movimiento de los trabajadores; Autodeterminación - Solidaridad - Paz.

\footnotetext{
${ }^{80}$ Constaba de tres etapas: “a) ver los hechos, la situación, la vida; b) juggar de acuerdo a la doctrina cristiana; c) obrar, individual y colectivamente para lograr los fines buscados". Abelardo Soneira, "La Juventud Obrera Católica en la Argentina: de la secularización a la justicia social”, Revista Justicia Social, 5:8, 1989, 77.

${ }^{81}$ CPL, Instructivo para la realización..., op. cit, 21-22 (el resaltado es nuestro).

82 Soneira, op. cit., 77.

83 En el sentido que el proceso de concientización parte de esa realidad (y no de algo distante o desconocido), la cuestiona y complejiza, y en dicho trayecto va generando un proceso de pensamiento crítico. Sin embargo, es necesario señalar que el propio método de la JOC partía "de la necesidad que el ambiente exigía para ser cristianizado. De éste se tomaban su tradición y sus problemas particulares, para que desde ellos se resignificara el catolicismo...". Leantro Bottinelli y otras/os, "La JOC. El retorno de Cristo Obrero", Fortunato Mallimaci y Roberto Di Stefano (comps.), Religión e imaginario social, Bs. As., Manantial, 2001, 83. Existe una correspondencia además entre los tres momentos del método jocista y el proceso de concientización en Freire: pasando por una fase donde el oprimido identifica sus problemas (sensibilización), luego reflexiona sobre la causalidad de los mismos (toma de conciencia), para finalmente actuar sobre ellos (acción transformadora).
} 
De un modo general, podemos decir que en el Ciclo I presentaban un diagnóstico -acompañado de datos cuantitativos- de la situación y relación del trabajador con su entorno geográfico, económico, social, político y cultural. El tono es de denuncia, enfatizando los mecanismos de explotación y opresión en que viven los pueblos latinoamericanos; el nivel (y multiplicidad) de las desigualdades. Se identifica a los beneficiados de dicha situación (compañías extranjeras y/o gobiernos antinacionalistas) y a las jerarquías eclesiásticas como cómplices del militarismo y de las democracias ficticias (en tanto limitadas a asuntos políticos). Se destacan los aspectos negativos de un desarrollo industrial y/o técnico dependiente, vinculado a intereses de los países ricos ${ }^{84}$ o empresas trans/multinacionales. Denunciando a los titiriteros detrás del Panamericanismo, la integración latinoamericana -entendida en un sentido económico, social, político y cultural- es presentada como solución a la dominación imperialista del "patrón EE.UU.". La sesión dedicada al estudio de la reforma agraria se detiene en la cuestión de la desigual tenencia de la tierra, planteando la necesidad de que aquella se dé en un marco de cambio total de la sociedad. Al tratar los temas del empleo y el desempleo, la alimentación (el hambre) o la seguridad social y la vivienda, el eje está puesto en mostrar la incapacidad del sistema capitalista para resolver estos derechos. La empresa aparece como centro de explotación, mientras que, luego de explicar qué es la plusvalía, se señala que el aumento de salarios (un robo institucionalizado dentro del sistema capitalista) no soluciona el problema de la explotación. Se marca la escasa organización de la fuerza laboral en la región, sumado a que, por estar sus organizaciones subordinadas a distintas esferas de poder, no responden a las aspiraciones de los trabajadores. Frente a ello definían la necesidad de construir organizaciones populares libres y voluntarias, democráticas, autónomas, revolucionarias e ideológicas, unitarias y con conciencia de clase. El folleto sobre educación se dedicaba a denunciar la funcionalidad de la "educación bancaria" -en términos freireanos- al sistema capitalista, y el rol de los medios de comunicación como instrumentos para transmitir sus valores y normas.

El último folleto concluye planteando -a modo de continuidad con los temas que serían objeto de reflexión en el Ciclo II- que:

Los países pobres deberán plantearse un camino revolucionario que los lleve a transformar su propia realidad en cuatro niveles distintos a saber: a) El nivel de los valores, para generar un hombre nuevo. b) A nivel de estructuras económicas. Transformar los modos de producción y cambiar cualitativamente la concepción de la propiedad, destinos de los ingresos y objetivo de la actividad económica. c) En el plan social. Creación de verdaderos canales de participación que posibiliten la autogestión social. d) A nivel político: Mecanismos que aseguren demandas de igualdad, autenticidad y participación en las decisiones más transcendentales para el país ${ }^{85}$.

Los temas debatidos durante el Ciclo II vienen a dar respuesta, desde el Movimiento de Trabajadores, al diagnóstico del ciclo anterior. Aquí se trabaja sobre la base de fragmentos de textos previos, organizados en una primera parte denominada 'Declaración de principios de la CLAT' y otra sobre sus 'Posiciones'. Así, arriman a las bases un conjunto de documentos programáticos fundamentales elaborados en distintos momentos de su historia. Cuestiones como la persona o la familia, la dignidad o la igualdad, y el trabajo como medio de realización se abordan en clave humanista. Las referencias a la promoción de la persona humana y al desarrollo integral de todo hombre y de todos los hombres, se repiten insistentemente a lo largo de los ocho fascículos. El Bien Común, la prosperidad colectiva, orientaban la organización económica y social de la propiedad y de la empresa. Proponían "la democratización de la propiedad de los bienes de producción a través de la gestión

\footnotetext{
84 Divide y asocia "países pobres" a Tercer Mundo y "países ricos" al "mundo de los países desarrollados de economía de mercado de Occidente y al mundo de los países socialistas industrializados de economía centralizada". CLAT, PCEI, Ciclo I..., op. cit., Tomo XV, 7.

85 Ibid, 24.
} 
comunitaria de todos los productores, cualquiera sea su aportación y especialidad, para lograr una efectiva socialización de los medios de producción". Si bien ello colocaba los bienes al servicio de todos los hombres, permitiendo su realización, promoción y desarrollo integral -siempre en términos personales y colectivos-, debía evitarse el estatismo, la tecnocracia y la burocracia que llevan a la despersonalización. Citando un documento de 1971, se volvía a poner sobre la mesa al socialismo comunitario como la "síntesis histórica de la democracia autentica e integral: personalista, pluralista, comunitaria, inspirada en los valores originales del Movimiento de los Trabajadores y en los valores del humanismo cristiano". En esta tónica, el desarrollo no podía imponerse a los países subdesarrollados desde afuera; por el contrario, éste no se lograría sin liberación, sin revolución, ni integración en una Gran Nación Latinoamericana, y sin la planificación en base a esquemas y modelos propios de los trabajadores. Se rechazan por tanto las formas de colonialismo tecnológico y cultural funcionales a la estrategia de modernización del capitalismo (desarrollismo), que imposibilitaban la liberación. La democracia real (social y económica, y con libertad política y personal) era entendida como la participación total del pueblo en la construcción de su porvenir; suponía la descentralización del poder, del capital y del Estado, creando como nuevo centro el del pueblo organizado. Todo lo anterior, y ésta es otra concepción que se repite, debía realizarse "desde abajo y desde adentro" del Movimiento: sin participación de los trabajadores organizados no habría una real transformación ni económica ni política. Palabras como autoorganización, autogobierno, autonomía de pensamiento y acción, poder autónomo, evocan repetidamente esta concepción del poder y del tener ${ }^{86}$.

Nos detuvimos en la descripción de los contenidos de los cuadernillos puesto que, al ser un material elaborado de modo centralizado para las bases del movimiento, nos permite vislumbrar cuáles eran las temáticas definidas como prioritarias y con qué enfoque se abordaron. En su recorrido es posible advertir que se entrelaza una contundente denuncia al capitalismo como sistema, apelando inclusive a categorías y al instrumental analítico marxistas; crítica a la que se viene a dar respuesta desde el humanismo cristiano y el desarrollo integral -al que se le agrega el calificativo 'autónomo'-. Al "desarrollo integral del hombre, de todo hombre y de todos los hombres" puesto en circulación por el Concilio Vaticano II, ya no podía concebírselo sin denunciar al neocapitalismo y sus planes que profundizaban el subdesarrollo; ni a la promoción y liberación (individual y colectiva) sin entender a los trabajadores como "fermento y vanguardia" de una urgente "revolución humanista, democrática y comunitaria" $" 87$.

Efectivamente circulaban por el imaginario de la CLAT elementos de la teoría de la dependencia, de la teología de la liberación, de la teología del desarrollo de Lebret, del socialismo personalista de Mounier, conjugado con una importante referencialidad práctica en el proceso de autogestión yugoslavo. Ninguno de los conceptos que recoge es inequívoco en sus interpretaciones, ni éstas fueron estáticas en el devenir de la propia Central. En todo caso, cabe resaltar que la lente desde la cual la CLAT los articuló fue su impronta latinoamericanista y basista -en la significación social y antropológica, pero sobre todo pedagógica, derivada de la praxis de las Comunidades Eclesiales de Base ${ }^{88}$. Esto es, la convicción de que la complejidad regional sólo podía ser comprendida cabalmente desde una teoría original y, más aún, que las respuestas políticas de transformación de dicha realidad sólo serían válidas en la medida que fuesen elaboradas y asumidas por las y los propios trabajadores. Pero si la CLAT procesó parte del fructífero diálogo entre marxismo y cristianismo que tuvo lugar en otras latitudes, como veremos a continuación, lo hizo en términos teóricos, pero no políticos.

$86 \mathrm{Si}$ bien hemos evitado el entrecomillado, se respetó el sentido y vocabulario utilizado por la CLAT.

87 CLAT, PCEI, Ciclo II..., op. cit., Tomo VIII, 7.

88 Véase Leonardo Boff, Y la Iglesia se hizo pueblo, Santander, Ed. Sal Terrae, 1986, 109-110. 


\section{Balance y redefinición estratégica}

Si en sus inicios el PCEI fue propuesto a la propia CMT como modelo a seguir para encarar una batalla cultural contra el capitalismo que debía darse a nivel planetario ${ }^{89}$, a medida que se fue desplegando, el balance interno que realizó la dirección de la UTAL fue muy crítico respecto de los resultados alcanzados. Crítica que tiene diversas aristas, y que ayuda a visualizar las dificultades con que se toparon los responsables de formación en el camino por concretizar su proyecto formativo hacia las bases del Movimiento.

Por un lado, al nivel de los cuadros de dirección y responsables de formación los Seminarios Ideológicos a nivel latinoamericano o nacional (cuyo objetivo era nutrir la marcha del PCEI) debieron posponerse o nunca llegaron a realizarse; señalándose, además, cuando existieron, su desconexión con el trabajo previo de los círculos (desdibujándose su objetivo fundamental: sintetizar la elaboración de estos ámbitos para elevar dichas reflexiones a la CPL). Al nivel de bases, la implementación de los círculos resultó ser muy dificultosa, sobre todo a partir de 1975, cuando disminuyen considerablemente y no se logra mantener un seguimiento de los mismos. Esta fue la situación vivida particularmente en los ámbitos campesinos, donde si bien se había arrancado en todos los países, se encontraron muchas dificultades para sostener la dinámica de trabajo. Entre las razones se aducía que "no hay animadores; la gente es muy indolente; el material no es adecuado" 90.

Así, dos fueron los problemas fundamentales según la autoevaluación de la CLAT para el avance del proyectado PCEI. Por un lado, la limitada comprensión por parte de las conducciones políticas nacionales de sus objetivos y mecanismos, señalándose que "el activismo inmediatista ha ido paralizando e impidiendo el Desarrollo del Proceso" 91 . Asunto fundamental si recordamos que, si bien los aspectos pedagógicos estaban a cargo del ILATES/UTAL y la coordinación política en manos de la CPL, la responsabilidad de garantizar su efectiva ejecución y seguimiento recaía en los centros nacionales. Por otro, la falta de una buena estructura de Formación Abierta en los distintos países sobre la cual se suponía el PCEI debía apoyarse-, hizo que este último sólo pudiese "incentivar hacia la Formación Abierta y no arrojar propiamente una elaboración ideológica"92. En otras palabras, el punto de llegada fue el que debía haber sido el de partida.

Era evidente la escasez de recursos materiales y humanos. Pero también es necesario agregar que allí donde logró implementarse del modo en que fue planificado, se obtuvieron significativos resultados. Es el caso de Venezuela, donde el Instituto Nacional de Estudios Sociales (INES), tal como se esperaba de estas instancias, tuvo un rol activo que redundó en que los y las participantes del PCEI "se incorporan en forma militante a la lucha sindical" 93 . Ello fue producto de la realización de seminarios a los que asistían militantes procedentes de las distintas regiones del país, donde se capacitaban como promotores de círculos de estudio. Sumado a ello el INES sí cumplió con la realización de varios

\footnotetext{
${ }^{89}$ Discurso de Emilio Máspero ante el XVIII Congreso de la CMT de 1973. World Confederation of Labour (WCL/CMT), Solidarity and liberation. Prospects and bases for a WCL strategy. XVIIIth. Congress. Evian, 25-28.09.1973. Rapporteur: E. Máspero, 414420, en IISH.

${ }^{90}$ UTAL, Compilación de las evaluaciones de los Departamentos y Centros de la UTAL, Apartado "Elementos a considerar en la Evaluación de la Sección Campesina del Departamento de Formación de la UTAL", San Antonio de los Altos, noviembre 1975, 44, en KADOC $\mathrm{BE} / 942855 / 757 / 1045$.

91 UTAL, Compilación..., op. cit., Apartado "Informe evaluativo de la sección Proceso Ideológico y Formación Abierta del Departamento de Formación", 3.

92 Ibid, 5.

93 CLAT, Vocero..., Año VIII, septiembre-octubre 1974, N65, 2. Según la subdirectora del INES, "Hasta hace algún tiempo se experimentaba cierto ausentismo de los trabajadores en la Asamblea y otras actividades; hoy en cambio, existe una mayor participación en la discusión de los problemas y en la toma de decisiones para la mejor marcha del Movimiento de los Trabajadores". Idem.
} 
Seminarios Ideológicos, donde además de la discusión de contenidos se evaluaba el desenvolvimiento de los círculos a nivel nacional.

Detrás de dicho balance, realizado hacia fines de 1975, se advierte la situación de fragilidad en que se encontraba la Central. El nivel de conciencia y compromiso de sus bases, militantes e inclusive cuadros, parece no corresponder con lo que de éstos se buscaba, resulta distante de lo que aparece al realizar una lectura de la prensa, declaraciones y posicionamientos oficiales. En esta coyuntura, pero atendiendo a las futuras resoluciones del VII Congreso de 1977, se advierte que la "formación básica de carácter masivo", si bien no se abandona, pasará a un segundo plano. En la propia fundamentación de la CLAT, el contexto de endurecimiento de las dictaduras latinoamericanas tornaba necesario reforzar la "formación de cuadros para la elaboración teórica y política"94. Argumentaban, además, la necesidad de acompañar cualitativamente el proceso de crecimiento cuantitativo que habían experimentado, cuestión que por haber estado ausente había provocado fuertes conflictos internos. En este último sentido comienzan a aparecer críticas y acusaciones relativas a la falta de organicidad con que se desarrollaba la formación, sin ajustarse a su línea política. Tomaremos este último punto para explicar el mencionado giro en su política de formación, ya que se vincula con el desarrollo del PCEI y el balance anteriormente esbozado.

A partir de 1976 aparecerán con cierta recurrencia en la prensa declaraciones del secretario general y adjunto, donde advertían que muchas de sus organizaciones afiliadas estaban siendo "infiltradas" por el marxismo-leninismo; denuncia que iba unida a un llamado a "supervigilar" el proceso de formación. Así, en un acto en Colombia a fines de ese año Máspero sentenció: "Alerto a todos ustedes a supervigilar lo que se enseñe en este centro de formación tanto en materia de animadores, como documentos de apoyo, bibliografía y otros aspectos de la formación. No podemos aceptar en modo alguno ningún tipo de contrabando político ni ideológico en nuestros centros de formación..."95. Se refería al reparto de materiales sobre sindicalismo de orientación leninista, ocurrido en el INES colombiano unos meses antes ${ }^{96}$. De igual manera se quejó de "contrabando ideológico" cuando en noviembre de 1975 apareció la hoz y el martillo en una portada del periódico Unidad Sindical, de la ecuatoriana CEDOC $^{97}$.

Significativamente, y más allá de la crítica hacia las falencias en la implementación del PCEI y sus magros resultados, cabe señalar que existió cierta correspondencia entre los lugares en donde éste tuvo un mayor grado de desarrollo y la ocurrencia de procesos de ruptura y/o cuestionamiento a la dirección de la CLAT. Fue la situación en Honduras, República Dominicana, Colombia y Ecuador. Estos cuatro países son los que sostienen mayor cantidad de Círculos de Estudio durante 1975 -cuando ya la UTAL alerta sobre su decadencia-98; a la vez que son los ejemplos denunciados por el secretario adjunto

${ }^{94}$ CLAT, La CLAT en la encruijada..., op. cit., 106-119.

${ }^{5}$ CLAT, Informativo $C L A T$..., Año 1, Nº9, diciembre 1976, 3.

96 “... y para colmo de todo esto, hay gente nuestra que imprime, distribuye y difunde en nuestro Instituto de Formación y para nuestros dirigentes, documentos que expresan, lo que los grupos marxistas-leninistas desde afuera tratan de imponer a la CGT para obligarle a cambiar su línea...”. Carta de Máspero a Víctor Baena López, San Antonio de los Altos, 11/08/76, citada en Wahlers, op. cit., 320 .

${ }_{97}$ Carta de Máspero a la Directiva de la CEDOC, Caracas, 07/12/75, citada en Ibid, 305. Manteniendo la sigla, en 1972 ésta pasó de denominarse Confederación Ecuatoriana de Organizaciones Sindicales Cristianas a Confederación Ecuatoriana de Organizaciones Clasistas. Es interesante destacar que, todavía en 1978, en ocasión de su XII Congreso Nacional y mientras la CLAT hacía tiempo enarbolaba la bandera de la "democracia real" como sinónimo de nueva sociedad, la CEDOC seguía sosteniendo la consigna "por un socialismo comunitario". Véase la fotografía en CLAT, Informativo CLAT..., Año 3, N²4, mayo 1978, 8.

98 Según el Informe del XIV Consejo Latinoamericano de la CLAT (Caracas, agosto de 1975), la cantidad de círculos era respectivamente: 105, 50, 98 y 71, citado en Wahlers, op. cit., 269. Un relevamiento realizado en 1979 muestra que son estos mismos países -ahora se sumaba Argentina- donde se contaba con equipos de formación consolidados en los institutos nacionales. UTAL, Circular 013/79. Asunto: Programa de Formación de Formadores. Proyecto: Programa de Formación de Formadores, I Parte, 1-2, San Antonio de los Altos, 24/05/1979, en KADOC BE/942855/757/340. 
Eduardo García, en donde los "grupúsculos divisionistas" de "burguesitos" con concepciones "elitescas" han intentado dividir a las organizaciones de la CLAT 99 . En el caso de Ecuador, fue la propia CLAT la que identificó en las tareas de promoción del PCEI que desarrolló el Instituto Ecuatoriano de Formación Sindical (INEFOS), la causante de la radicalización de sus bases en varias federaciones ${ }^{100}$.

Dicho de otra manera, si bien las fuentes son insuficientes para profundizar en este aspecto, es posible pensar que allí donde sí logró desenvolverse, el PCEI abrió un proceso de profundización por izquierda del arsenal discursivo que la propia CLAT puso en circulación. No se trataba de cuestionamientos provocados por "infiltrados" desde afuera como argumentaban las dirigencias, sino de un proceso de radicalización que brotaba del seno del Movimiento de Trabajadores. Trazando cierto paralelismo, si el Concilio Vaticano II primero y Medellín después, a su vez recogieron la ebullición presente en el mundo católico y abrieron procesos de radicalización que la institución buscó contener ${ }^{101}$, el PCEI expresa una dinámica equiparable, habilitando un movimiento por la base que luego la propia dirigencia de la CLAT intentó frenar o controlar ${ }^{102}$.

Así fue cómo, la inquietud por desarrollar una formación político-doctrinaria destinada a cuadros de conducción, que había surgido hacia fines del año '75 desde la UTAL, se tornó a partir de las definiciones del VII Congreso en un "objetivo prioritario". Esta tarea debería ser asumida por las respectivas estructuras existentes, pero colocándose "bajo neto control y seguimiento político y estratégico"103. Es interesante señalar que quien estuvo a cargo de los mencionados Seminarios de Formación Superior de Conducción Global Política y Estratégica que dieron la impronta a esta nueva etapa, fue Oscar Martínez, hasta entonces responsable de poner en marcha el Ciclo I del PCEI ${ }^{104 .}$

\section{El socialismo en disputa}

$\mathrm{Si}$ retrocedemos unos años, vemos que la disputa contra los "infiltrados" marxista-leninistas desnuda, crudamente, una preocupación más amplia, que remite a las formas de construcción y organización políticas. La experiencia chilena resultó a la CLAT emblemática para desplegar su concepción en este punto. El golpe había coincidido, además, con el arranque del Ciclo I del PCEI. Luego de una cruda condena a lo que rápidamente identificaron como "la noche oscura del fascismo", la Central realiza una serie de reflexiones que vinculan ambos procesos en torno a la discusión de fondo que estaba planteada: cómo llegar al socialismo. Críticos del modelo leninista, recuperan la concepción comunitarista cristiana en la que abrevaban las Comunidades Eclesiales de Base ${ }^{105}$. Habiendo criticado previamente el "modelo de socialismo que se estaba imponiendo en Chile... con claras muestras de intervenciones extranjerizantes", las que significaban "un mero cambio de patrón y una apropiación del poder y de los medios de producción en manos de una tecno-burocracia estatal" que no hacía sino desplazar a los y las trabajadores de la gestión y control del proceso "impidiendo que surjan fórmulas

\footnotetext{
99 "Lo han intentado hacer aquí en Ecuador y fracasaron, lo intentaron hacer en Colombia y en el último Congreso Nacional de la CGT las bases los aplastaron, lo han intentado hacer en República Dominicana y hoy regresan pidiendo perdón diciendo que se equivocaron, lo tratan por otra parte de hacer en Honduras". CLAT, Informativo CLAT..., Año 2, N¹1, marzo 1977, 9. 100 Véase Wahlers, op. cit., 316.

101 Tomamos esta lectura de Silva Gotay, op. cit., 45, 61 y 65.

102 Llamativamente, el propio Máspero, durante el I Seminario Nacional Ideológico organizado por la CEDOC en Quito en 1974, incentivaba a los más de 120 asistentes a levantar "la bandera de la rebelión ideológica, de la revolución cultural". CLAT, Vocero..., Año VII, N65, septiembre-octubre 1974, 14.

103 CLAT, La CLAT en la encrucijada..., op. cit., 107.

104 CLAT, Vocero..., Año IX, Nº7, enero-febrero 1975, 15.

105 Es decir, un modelo circular y comunitario de Iglesia, construido en y desde las bases del pueblo; que recupera la forma Iglesia-comunión del primer milenio. Véase Boff, op. cit., capítulos 6 y 7.
} 
originales de autogestión de los trabajadores no sólo en la economía sino en toda la sociedad chilena..."106, arremeten:

la concepción leninista de la vanguardia profesional iluminada y aristocrática impulsa una revolución para los trabajadores pero no de, por, entre y con los trabajadores. ... no se compadece con el lema histórico de que solo el pueblo salva al pueblo, y fatalmente tiende a caer en dinámicas aristocráticas y exclusivas que manipulan al pueblo, pero no le permiten ser el sujeto histórico y decisivo. ... La CLAT marca un camino en esto: el proceso colectivo de elaboración ideológica: que todos los trabajadores participen en la elaboración de la nueva sociedad que debe reemplazar a la sociedad capitalista... ${ }^{107}$.

Más claramente, en el contexto de ruptura de la CEDOC anteriormente mencionado, el secretario adjunto, E. García, afirmaba estar "contra la concepción elitesca de dirección de la sociedad. Es por esta misma razón que rechazamos la concepción marxista leninista de que el partido es la vanguardia lúcida que piensa y decide, mientras que las organizaciones de trabajadores son las organizaciones de masas que conducidas por el partido realizan la acción de confrontación en función de los objetivos de aquel"108.

A su vez, es necesario remarcar que estas definiciones, que a priori podrían aparecer como un giro conservador, es acompañado por una serie de definiciones y posicionamientos en términos clasistas. La propia Central va a autodenominarse como una "organización de Clase, de Masas y de Confrontación"109, que brega "por un movimiento sindical no-alineado, autónomo, democrático, unitario, clasista y solidario"110. Más interesante aún, en el contexto del encuentro de la CELAM de 1978 en Puebla, realizaban un balance crítico de los resultados de Medellín argumentando que el "hincapié en los "pobres y marginados" había llevado al asistencialismo y paternalismo. Por ello, era perentorio que "Puebla 78 asuma a estos mismos pobres y marginados como trabajadores, como clase trabajadora con su conciencia de clase, con sus valores e intereses de clase, con sus necesidades y aspiraciones de clase, con su proyecto político histórico de nueva sociedad como la quieren y entienden los trabajadores"111. Aunque como vimos, esta concepción ya estaba presente en el trabajo de base promovido a través del primer Ciclo del PCEI ${ }^{112}$. Vale decir, que estos posicionamientos que a primera vista pueden parecer contradictorios, en realidad echan luz sobre el entramado identitario de la CLAT, y nos conduce a una segunda discusión: entre las múltiples declaraciones cristianas en favor de un socialismo más bien "genérico" 113 , de qué socialismo hablaba la CLAT?

Aquí la cuestión se torna más difusa, y fue en parte lo que motivó conflictos internos. Como hemos expuesto, la definición en torno a una sociedad de nuevo tipo que develó a la CLASC/CLAT debía ser un punto de llegada del conjunto del Movimiento. Si bien en el VI Congreso de 1971 -en el cual se proyecta el PCEI- se esbozó como posibilidad el "socialismo comunitario", años más tarde, durante el VII Congreso -que debía retomar y dar forma final a los resultados de dicho Procesodefinen más claramente su contorno. Esta nueva sociedad estaría signada por la democratización "del

106 CLAT, Vocero..., Año VII, N55-56, octubre-noviembre 1973, 3.

${ }^{107}$ Idem (resaltado en original).

108 CLAT, Informativo CLAT..., Año 2, Nº11, marzo 1977, 9.

109 CLAT, Sólo el poder..., op. cit., 178.

110 CLAT, Informativo CLAT..., Año 3, №22, marzo 1978, 10-11.

111 CLAT, Informativo CLAT..., Año 3, №27, agosto 1978, 20.

112 "Cuando el trabajador está consciente de pertenecer a una clase y se siente solidario con sus miembros, a partir de comprender su situación de subordinación y explotación dentro del sistema capitalista adquiriendo claridad como sujeto bistórico más importante para luchar por la transformación social, entonces hay conciencia de clase". CLAT, PCEI, Ciclo I..., op. cit., Tema XIV, 15 (resaltado en original).

113 Silva Gotay, op. cit., 230-231. 
poder, del tener y del saber", es decir, por la socialización de los medios de decisión, de producción y circulación, como de la cultura, la ciencia y la tecnología". Por su propia dinámica, esta "democracia real e integral" basada en la autogestión (entendida en términos sociales, económicos y políticos) generaría un nuevo tipo de relaciones sociales basadas en la solidaridad y la igualdad ${ }^{114}$.

Siendo que los procesos educativos son relacionales y hablan de aquellos marcos más amplios en que se desenvuelven, el recorrido por el proyecto pedagógico de la CLASC/CLAT y la experiencia del PCEI en particular nos permite aproximar una caracterización a esta organización, en una discusión que fue nodal para la época y para la propia organización. Para la CLASC/CLAT, el énfasis siempre estuvo puesto más en el cómo que en el qué.

\section{Reflexiones finales}

A lo largo de estas páginas hemos buscado problematizar la caracterización político-ideológica de la Central Latinoamericana de Trabajadores, desde sus orígenes en 1954, fuertemente vinculados al sindicalismo socialcristiano en la región, hasta fines de la década del setenta, en que no sólo recrudece el contexto regional por el avance de las derechas sino que se inicia otra etapa de la organización, menos propensa a los cambios radicales. En dicho recorrido se produce un claro proceso de radicalización, que sin embargo no puede ser pensado en términos lineales, y en el cual se dibujan y desdibujan sus definiciones o contornos identitarios. ¿Cristianos o socialistas, revolucionarios o reformistas? Las interpretaciones en clave dicotómica obturan la posibilidad de advertir que fue en esa misma tirantez en que la CLASC se fue desarrollando con sus características específicas. Como para tantas otras organizaciones de la época, éstos no resultaban polos irreconciliables, aunque ello tampoco significó que coexistieran sin contradicciones.

Para ensayar una delimitación más clara sobre este actor poco explorado, elegimos analizar su proyecto pedagógico, en particular aquellas actividades que buscaban formar políticamente a los y las trabajadores de base, considerando que en dicha praxis puede advertirse el sentido con que se buscaba orientar la acción del Movimiento. Si elegimos focalizar la mirada en el Proceso Colectivo de Elaboración Ideológica fue porque este condensa la preocupación de la dirección de la CLAT por atender a los aspectos ideológico-culturales de la lucha -produciendo una revolución cultural a través de una formación sistematizada-, necesarios para llegar a construir el poder organizado de los trabajadores y proyectar una nueva sociedad.

Como vimos, las instancias educativas fueron consideradas como parte de la dinámica conflictual, y en tanto tal las primeras potenciaban la segunda. Estuvieron plasmados en su praxis pedagógica los elementos conceptuales que tensionaron su identidad: una crítica a la explotación capitalista (que según los momentos enfatizó contradicciones de clase o imperialistas -la más de las veces-); una definición del sujeto revolucionario que apelaba a los trabajadores entendidos en sentido amplio (considerando las especificidades del trabajo en la región); una economía socializada y un ordenamiento político participativo donde el individuo no se diluía en lo colectivo; un socialismo latinoamericano que apelaba a elementos del humanismo cristiano, comunitarios y autogestivos.

Impregnado por la concepción pedagógica de la JOC, el PCEI mantuvo su estructura de funcionamiento aunque el sentido era resignificado y matizado con notas propias de la pedagogía crítica latinoamericana. A pesar de ciertos corrimientos en sus posicionamientos políticos, a través del análisis de los contenidos impartidos se observa que, en la delimitación de lo que debía ser la nueva sociedad se mantuvieron constantes ciertas referencias mientras que otras fueron más intermitentes. Entre las primeras encontramos la filosofía social del cristianismo como principio rector, nociones anticapitalistas

114 CLAT, La CLAT en la encrucijada..., op. cit., 181-187. 
y clasistas, tercermundistas y antiimperialistas. Entre las segundas, advertimos que el grito por la liberación y la revolución dejarían paso a reclamos de libertad y defensa de los derechos humanos, sintetizadas hacia fines de los setenta en la definición por una revolución humanista, democrática y comunitaria; cuando el socialismo comunitario vino a ser identificado con una democracia real e integral (social y económica, con libertad política y personal). Fue su basismo, es decir la confianza en la fuerza propia de los y las trabajadores autoorganizados (excluyendo de este universo a los agrupamientos político-partidarios) lo que los llevó a sostener el comunitarismo de raigambre socialcristiana como forma de construcción política. Es importante destacar que el PCEI fue expresión del momento de mayor radicalidad en el discurso y práctica de la Central. De allí las rupturas o cuestionamientos por izquierda que relatamos hacia el final del artículo, acaecidos sobre todo en aquellos países donde la experiencia había logrado un mayor desarrollo. De allí también el cambio de estrategia en su proyecto pedagógico, que supuso si no el abandono del proceso de formación destinado a las bases, un vuelco hacia una formación focalizada en los cuadros de conducción y que sería realizada bajo un encuadramiento mucho más cerrado, aproximándose a las lógicas partidarias de izquierda que tanto combatía. Así, tensionada por factores externos e internos, y con la riqueza que su proyecto pedagógico supuso, la CLAT no logró resolver la tensión entre reflexión y acción, entre formación política y acción sindical.

\section{Bibliografía}

Alexander, Robert, International Labor Organizations and Organized Labor in Latin America and the Caribbean. A History, California, ABC-CLIO, 2009.

Benedetta, Calandra y Marina Franco (eds.), La guerra fría cultura en América Latina, Bs. As., Biblos, 2012.

Boff, Leonardo, Y la Iglesia se bizo pueblo, Santander, Ed. Sal Terrae, 1986.

Bottinelli, Leandro y otras/os, "La JOC. El retorno de Cristo Obrero", Fortunato Mallimaci y Roberto Di Stefano (comps.), Religión e imaginario social. BsAs, Manantial, 2001, 69-116.

Córdova, Efrén, "El neosindicalismo cristiano en la América Latina: CLASC", Revista de Ciencias Sociales, 12:2, 1968, 255-295.

Dussel, Enrique, Historia de la iglesia en América Latina: medio milenio de coloniaje y liberación (1492-1992), Madrid, Mundo Negro-Esquila Misional, 1992.

Francis, Michael, "Revolutionary Labor in Latin America: the CLASC", Journal of Inter-American Studies, 10:4, 1968, 597-616.

Godio, Julio, Historia del movimiento obrero latinoamericano. Socialdemocracia, socialcristianismo y marxismo, 1930-1980, Caracas, Ed. Nueva Sociedad, 1985,

--- y Achim Wachendorfer, "Las internacionales sindicales", Nueva Sociedad, 83, 1986, 81-88.

Gordillo, Mónica, "Activismo sindical transnacional en el Cono Sur: algunas experiencias", Clepsidra. Revista Interdisciplinaria de Estudios sobre Memoria, 4:7, 2017, 68-83.

Horn, Gerd-Rainer, Western European Liberation Theology: The First Wave (1924-1959), Nueva York, Oxford University Press, 2008.

--- The Spirit of Vatican II. Western European Progressive Catholicism in the Long Sixties, Oxford, Oxford University Press, 2015.

--- y Emmanuel Gerard (eds.), Left Catholicism. Catholics and Society in Western Europe at the Point of Liberation 1943-1955, Lovaina, KADOC-Leuven University Press, 2001.

Löwy, Michael, Guerra de dioses: religión y politica en América Latina, México, Siglo XXI, 1999.

Máspero, Emilio, "Latin America’s Labor Movement of Christian Democratic Orientation as an Instrument of Social Change”, William D' Antonio y Fredrick Pike (eds.), Religion, Revolution, and Reform. New forces for change in Latin America, N. York, Praeger 1964.

Parcero, Daniel y Mario Morant, El sindicalismo argentino: de no alineado a la unidad global, Buenos Aires, CICCUS, 2016. 
Pasture, Patrick, Christian Trade Unionism in Europe since 1968. Tensions between identity and practice, Londres, Aldershot, 1994.

Rodríguez, Lidia, Paulo Freire. Una biografía intelectual. Surgimiento y maduración de la pedagogía del oprimido, Buenos Aires, Editorial Colihue, 2015.

Scodeller, Gabriela, "Sources for Latin American Research at the International Institute of Social History. CLASC/CLAT”, ERLACS, 98, 2015, 99-104.

--- "Political Training and Social Change in the 1960s and 1970s: the Educational Activities of the Latin American Central of Workers (CLAT)", ILWCH, 90, 2016, 93-110.

Silva Gotay, Samuel, El pensamiento cristiano revolucionario en América Latina y el Caribe. Salamanca, Ed. Sígueme, 1981.

Soneira, Abelardo, "La Juventud Obrera Católica en la Argentina: de la secularización a la justicia social”, Revista Justicia Social, 5:8, 1989.

van Voss, Lex Heerma, Patrick Pasture y Jan De Maeyere (ds.), Between Cross and Class: Comparative Histories of Christian Labour in Europe 1840-2000, Bern, Peter Lang, 2005.

Wahlers, Gerhard, Nace una alternativa, Miami, Saeta Ed., 1991.

\section{Fuentes}

Confederación Latinoamericana Sindical Cristiana (CLASC), Vocero del sindicalismo cristiano en América Latina, Caracas, 1967-1971.

- Formación de trabajadores para América Latina. Manual de Formación por el grupo responsable de formación de la CLASC, Caracas, FLACPO, 1971.

CLASC-DELAT, Los problemas de la educación en Latinoamérica, S/lugar, 1968.

Central Latinoamericana de Trabajadores (CLAT), Vocero del movimiento de los trabajadores comprometidos con la liberación de los pueblos de América Latina, Caracas, 1971-1975.

- Informativo CLAT, vocero del movimiento de los trabajadores comprometido con la liberación de los pueblos de América Latina, Caracas, 1976-1978.

- Proceso Colectivo de Elaboración Ideológica. Ciclo I: Diagnóstico de la realidad nacional, latinoamericana y mundial, Venezuela, FLACPO, sin fecha.

- Proceso Colectivo de Elaboración Ideológica. Ciclo II: Aportes de la CLAT al movimiento de los trabajadores, Venezuela, FLACPO, sin fecha.

- Proyecto UTAL, Volumen 2, Anexos III y IV, sin datos de edición.

- Una nueva educación en la perspectiva del Movimiento de los Trabajadores. Caracas, 1974.

- La CLAT en la encrucijada. Informe politico y de orientación presentado por Emilio Máspero, secretario general de la CLAT, a nombre del Comité Ejecutivo Latinoamericano, ante el VII Congreso de la CLAT, Caracas, FLACPO, 1978.

- Sólo el poder detiene al poder. Acuerdos del VII Congreso sobre programa de reivindicaciones, de organización y acción, sobre acción profesionaly sobre politica de organización de cuadros y formación global, Caracas, FLACPO, 1978.

Comisión Política Latinoamericana (CPL), Instructivo para la realización del Círculo de Estudios. Instructivo $N^{o}$ III, sin datos de edición.

Instituto Nacional de Estudios Sociales (INES) Venezuela, Primer Seminario Nacional de Actualización Ideológica, Caracas, Julio 1975.

Máspero, Emilio, El sindicalismo como instrumento de la revolución en América Latina, sin datos de edición.

Universidad de los Trabajadores de América Latina (UTAL), Compilación de las evaluaciones de los Departamentos y Centros de la UTAL. San Antonio de los Altos, noviembre 1975.

- Circular 013/79. Asunto: Programa de Formación de Formadores. Proyecto: Programa de Formación de Formadores, I Parte, San Antonio de los Altos, 24/05/1979.

- Diez años de la UTAL: Algunos aspectos evaluativos. San Antonio de los Altos, 30/04/1984.

World Confederation of Labour/Confederación Mundial del Trabajo (WCL/CMT), Solidarity and liberation. Prospects and bases for a WCL strategy. XVIIIth. Congress. Evian, 25-28/09/1973. 